\title{
Zayd Mutee Dammaj's Approach to History in The Hostage
}

\author{
Abdulrahman Mokbel Mahyoub Hezam \\ Department of English, Faculty of Arts, Taiz University \\ \& \\ Department of Languages and Translation, \\ Faculty of Science and Arts, Taibah University, Al-Ola, Saudi Arabia
}

\begin{abstract}
:
The study examines Dammaj's The Hostage (1984), the most famous Yemeni novel, as a historical novel. The study aims to investigate the concept of history used by the writer in the novel and compare it to the concept of traditional approach and the concept of new historicism. The researcher used the analytical approach to show the complexity of The Hostage as a historically situated text, as a creation of the re-thinking, on the part of Dammaj of the concept of history. The natural integration of history and fiction makes Dammaj a natural historian, extracting and presenting a single kernel of meaning. With his narrative art, he is trying to manipulate a continuous parallel between contemporaniety and antiquity. The novel is an attempt by the present in the form of fiction to give a meaning to the past in the form of history. The study concludes that Dammaj was able to use a new approach to history which is his own and which puts him closer to new historicism of European decent.
\end{abstract}

Keywords : Dammaj, historicism, The Hostage, Yemen

Cite as: Hezam, A.M.M. (2018). Zayd Mutee Dammaj's Approach to History in The Hostage. Arab World English Journal for Translation \& Literary Studies, 2 (2).

DOI: http://dx.doi.org/10.24093/awejtls/vol2no2. 9 


\section{Introduction}

Zayd Mutee' Dammaj(1943-2000) is a Yemeni author and politician. He wrote a number of short stories and fictional works including best known short novel The Hostage which was selected by the Arab Writers Union as one of the top 100 Arabic novels of the 20th century. The novel was published in 1984 and had been translated to many languages including English, German, Russian, French, and Hindi. Set in the late 1940's, the novel is an engaging story of a young boy taken from his family by the Yemeni Imamate as a means to ensure his family's political loyalty. It traces the boy's development to adulthood as servant or (Dwwaydar) in the Imamate's palace. In the novel Dammaj was able to combine fiction and history and use a personal story to give the readers a view of an important period in the modern history of Yemen. The relation between history and fiction has been a much debated topics in literary studies. The paper tries to examine the historyfiction dynamics in Dammaj's novel and find out the nature of his approach to history.

Of all the literary forms, the novel's connection with history has been the closest. History is considered the basis of most of the novels but novelists' concern with history varies. Some base their novels mainly on historical facts and characters and events while others treat the past only as a background to their stories. In other fictional works it is difficult to disentangle the fictional element from historical elements because the writer succeeded in blending the historical and the fictional so that they reinforce each other. Fleishman (1972) argues that the historical novel should be set in the past and its plot should include a number of historical events and at least one historically "real" person. He adds that, "when life is seen in the context of history, we have a novel; when the novel's characters live in the same world with historical persons, we have a historical novel" (P. 4)

\section{Traditional approaches to history}

A fiction, as established by the traditional historicists; the text and history are treated in isolation. This approach puts the literary text in the category of a mere history of histories as it gives history an objective and independent status apart from the text. A genuine historical novelist summons up a past epoch and shows men and women alive in it and behaving as they must have behaved in the circumstances. It requires meticulous fidelity to the truths of history; only a limited deviation as prompted by imaginative re-construction of history is permitted. Butterfield, (1971) says that, "A true historical novel is one that is historical in its intention and not simply by accident, one that comes from a mind stepped in the past"(p.5) Walter Scott and his novels are the best example of the traditional approach to history. In the domain of fiction it was Scott who most effectively attempted the process of reconstruction of the past and the sanctification of its ideas and institutions. He waved the magic wand of his imagination to invest the dead bones with flesh and blood to make the frozen fossils radiant with life and energy. This is what is seen in his novel Kenilworth (1821). It is concerned with the visualization of the external social conditions and manners as well as the external behaviors and actions of the personages connected with the

Arab World English Journal for Translation \& Literary Studies 
particular period of Queen Elizabeth. Scott has viewed his characters from the outside without focusing on the inner life.

There is yet another traditional approach to history. This is the organic conception of history of which John Locke may be regarded the most impassioned advocate in England. It sanctifies the past and makes it moulder of the present and traces human character, manners, and behavior against the wider context of the historical forces which have made them what they are. Man is portrayed in his public and social aspects, man as conditioned by factors outside himself, by his place and function in society and his relation to a historic past. Historic and social processes crystallize out his dramatis personae.

\section{New Historicism}

As against this concept of traditional approach there is the concept of new historicism which obliterates the dichotomous duality of history and a literary text. Instead of being in the tradition of traditional historicism and of Scott and Bwcke, Dammaj has set a new approach to history which is his own and which puts him closer to the new historicism of European decent. The traditional approach treats history as coherent and continuous. It talks of historical specifity - of fixed facts attached to a specific era. It extends itself to the present by becoming the context or the background of the literary text being written or produced at a time far detached from the past. Abrams (1993) explains this approach when he says,

History is not a homogeneous and stable pattern of facts and events which can be used as the /"the background " to explain the literature of an era or which literature can be said simply to reflect, or which can be averted to as " the material" conditions that, in a simple and unilateral way, determine the particularities of a literary text. (p.250)

In this explanation, skepticism is apparent at two points. First, the very nature of history has been questioned. at a particular point of time in the past- in an era- history is not taken either as" homogenous"- consisting of men and events that are all of the same type or as" stable"- steady and not likely to move or change. So in history there is no "pattern"- regularly repeated arrangementof "facts" and "events". So, history itself is no more a set of fixed, objective facts which the historical literary text has been supposed to rejuvenate, to recreate and reconstruct.

Second point emphasizes the doubt that arises on the reliability of such a historical narrative. The very dependability or reliability of such a literary text comes under shadow. The doubt is not unfounded. The historical literary fiction of Scott and Bwcke has now become part of the historical past itself- now forgotten because of its limited, timebound appeal, of its attachment to the dead past which stops it from linking itself to the ever-changing human life. The living text needs to be interpreted in terms of the living changing human life, in terms of its ideological and cultural constructs. Beyond its past it cannot live in vacuum and so it has to connect with them to gain significance beyond time. And that is the true nature and test of a real literary text. History should be made to interact with such a text; the text is expected to represent history in terms of ideological and cultural constructs that go on changing. This is the interaction and reciprocity of history and a literary text.

Arab World English Journal for Translation \& Literary Studies 
A literary text gets itself connected with, embedded in, history through" the network of institutions, beliefs, and cultural power-relations, practices and products that in their ensemble constitute what we call history. (Abrams, 1993 p 250)

In terms of these constructs, the artificial boundaries between fiction and non-literary texts, between fiction and history stand demolished. They really become subject to "interchanges of diverse elements and forces. (Abrams, 1993, p 250) For such an interaction, the new historicists have coined certain terms Abrams(1993) points out "The favored terms for such interchangeswhether between the modes of discourse within a single literary text, or between diverse kinds of texts, between a text and its institutional and cultural context are "negotiation","exchange","transaction",and circulation"(p. 250))

And such metaphors are intended not only to denote the two-way, oscillatory relationships among the components of a culture.(Abrams,1993) but also the relationships among literature, aesthetics, history, social institutions and human relationships. It is always a" two-way" relationship in which fiction and history interact with each other. Fiction and history grow together as interactive components to evolve together a new system of values which are ready to satisfy the new aspirations of diverse human beings. That takes the text to its future which involves the progression of humanity to a new destiny which always calls him and awaits him. The text, the fiction, takes history consisting of cultural constructs as the spring- board to jump towards a new future that enlivens the text as well as the human life. Fiction dealing with a stagnant life, with history as histories, itself becomes stagnant and dead; Scott and Bwcke are examples. Shakespeare and Shaw provide the other example. Shakespeare in his history plays and Shaw in his St. Joan have projected the present consciousness to discover or to import some significance or meaning into old events. They have dressed the past in the garb of the present to make it more meaningful. The historic literary creations of both writers are relevant, significant, and meaningful. And that is what a true literary text is expected to do- to conceive and inaugurate radical changes in the social power-structure of which the individual artist is a product and subject.

At this stage of movement of fiction towards future destiny of man starts the disconnection, divergence between the literary text, fiction and history. Then two processes, to borrow the terms from linguistics, of defamiliarisation and deconstruction start. Defamiliarisation starts the process of defamiliarising the literary text, fiction and readers with the past, starts distancing itself from the past in course of its movement towards the present and the future. This defamiliarisation works at several levels.

The first one starts with the text, the fiction, taking into account the fact that it cannot get all its meaning from history taken as one continuous story of events and characters. It has to be " shaped and informed by the circumstances and discovered specific" to its era.( Abrams 1993) It has to have its own 'constructs' created out of the ideal culture and passions of its own people and time. They cannot come from the past. For history, in course of time, does not work in a continuous way in between past and present. In between these two distant and different points of time, history becomes discontinuous, the process of deconstruction sets in because of so many interventions of 
the social forces in their multifarious shapes, sometimes converging and creating unity and sometimes diverging and creating disunity. That way, history as a fixed entity becomes a misnomer. Explaining this rupture between fiction and history Abrams (1993) says:

To mitigate the risk that they will unquestionably appropriate texts written in the past, they tend to stress that the course of history between the past and present is not coherent, but exhibits discontinuities, breaks, and ruptures; by doing so, they hope to" distance" and "estrange" an earlier text and so sharpen their ability to detect in differences from their present ideological assumptions. (P. 251)

On the pattern of Shakespeare and Shaw, the writer of fiction uses the past to inform the present culture with a meaning that can help in the exploration of the future. His subject has to be different from the historian's subject. At this level to use certain Freudian mechanisms of creating a text out of history ,"suppression", "displacement" and" substitution" are undertaken by the writer of fiction. Here, the task of the reader becomes much more difficult. Abrams(1993) argues that" the primary aim of a political reader of a literary text is to undo these ideological disguises and suppressions in order to uncover the historical conflicts and oppressions which are the text true, although covert or unmentioned, subject matter."(P. 252)

\section{The Concept of History in The Hostage}

A close reading of the novel The Hostage shows that it $i$ a creation of the re-thinking, on the part of Dammaj, of the concept of history very much similar to that of new historicism analyzed above. No doubt, the fiction sources its material from history. And critics are ready to accept it as a "historical novel". Here is al-Maqalih, (1994) putting his ideas in his essay" Introduction: Literary Background"

If it is true as has been said that the historical novel makes a people live its history a new, then; The Hostage' which is in some degree a historical novel, has succeeded, for all its fictional characters in inducing the reader to grasp the most important aspects of the life of a decade- Yemen in the forties- which is still close to us today, a decade rich in specific local events that reflect attempts to lay foundations within a context of turbulent change and bring to an end the stagnation and rigidity of the regime as a whole" (p.18)

This is a partial statement of truth. In actual fact, the real nature of fiction is revealed only with an understanding of the sound intellectual context in which it has really been written. A subtle deep study of the novel reveals that it is not just a common historical novel in the tradition of traditional historical narrative.

The novel is a product of a speculative engagement with history. Dammaj is not a writer who seeks to present an objective description of the past. In fact Dammaj, in his novel shares with new historicism a suspicion, to use Branningan's words to explain historicism," of the practices of history as the objective description of a knowable past or as the empathetic recreation of that past"( Branningan ,1998). Both Dammaj and the new historicism reject the model that informed 
traditional literary history- relating literary texts to singular trends which are taken to characterize a particular period. From this past, obsessed with singular trends and a particular period, they have turned their attention to the past consisting of very diverse configurations of beliefs, values and trends, often coming into conflict and contradictions with each other. Naturally this concept leads to the realization that historical narrative is an important cultural phenomenon. It is here that fiction and fiction writer come to the fore. It is here that fiction starts the processes of defamiliarisation and deconstruction of history. Relegating history to its own past, Dammaj as a writer, becomes concerned with the way history and historiography impacted upon culture, upon the sociohistorical milieu in which he was living. This is the complexity of the novel The Hostage as a historically situated text.

The search for social and cultural relevance of history starts by decoding the cultural signs or symbols by reading the thoughts, feelings and fantasies of the protagonists within specific historical and political contexts. Dammaj in his fiction has written a history of humanity around discontinuity or interruption. He uses his fiction as an instrument to present a history, not in terms of a story of the past but in terms of a story of humanity, in terms of culturally privileged and culturally marginalized protagonists and in terms of how the latter try to subvert the former. The latter try to subvert the former, and resist the dominant culture in the text. That establishes the subversive nature of fiction. It establishes the fact that the worn social order produces fault lines through which its own criteria of plausibility fall into contest and disarray

This fact turns Dammaj's fiction into a particular kind of narrative, a story of conflict between individual consciousness and the collective historical agents of the society, a story of the quest for a new, more equal and more humane society that can better accommodate a new sense of self. The Hostage is an attempt to squeeze out of the conflicting and disarrayed historical forces and authentic concept of self that can give a true identity to an individual and, through him, to humanity as a whole. To those marginalized by society and by history, a sense of identity, as constructed through impersonal and social relations of power as manifested in historical forces, is essential. Acceptance of this essential fact of life gives the novel a distinctively modern plot that presents a logical progression of events toward a vision of social change based on the gradual recognition of the value of construing human identity in terms of relationship and dispersal.

At first one may think that what Dammaj is out to do is to tell the story of an ordinary individual who happens to be a hostage and falls in love with a royal woman. But a deeper reading shows that the protagonists of the novel are in search for their self-identity so that they can relocate their self lost in the mire of history. The hostage and Sharifa Hafsa have their own legitimate searches. They have been living at such a moment in the history of their socio-cultural life when they feel and think that with their efforts, they can bring about a substantial and significant change in the society and culture. This change will be reflected in their individual lives. That is how they look upon history; is a history that can be subjected to change with the efforts of the individual. The novel is a narrative of these efforts. So, in a way, these individual characters are trying to create a fictional narrative of their own within the historical narrative of the past. They try to mediate between these two narratives- history and fiction, the historical consciousness and the 
individual consciousness, the external world with historical specifity and fixity and the individual's desire for change.

This mediation is possible only with symbolism. Naturally, these individuals transfigure themselves into significant symbols of the different cultural constructs which may be used for transformation. One can even hazard to say that the Hostage or the new dwwaydar( a word used to call the young man taken as a hostage in the Imam's palace) and his friend the old dwwaydar are the reverse and the obverse of the same medal. While the ill dwwaydar is the deceased present the Hostage is the future. The former is totally submissive. The Hostage, on the other hand, is individualistic. He is tormented by his physical inability to revolt, his habitual submission to the royal family, and the conflict between his love for Hafsa and his self-esteem. As a consequence a complementary narrative is encoded within the novel that has the perspective of history. And that is the remarkable point of Dammaj's art. Fiction is encoded within history, where the thoughts, feelings, and fantasies of the protagonists in the text are discussed within the historical frameworks, and where history becomes reconfigured through individual memory and popular consciousness. When one enters the domain of individual memory and consciousness he is in the territory of fiction. The readers too have to negotiate in this dialectics of history and fiction. Here the protagonists of the novel come to their aid with their self-created symbolism. The novelist is nowhere; is neither with the readers nor with the characters. He has kept himself apart, far away from both, as if he did not exist.

That explains the use of the first person point of view in the novel. The new, younger dwwaydar is the narrator - narrating the experiences while still undergoing the experiences. The subjective and the objective have been so perfectly coalesced that the necessity of the third person narrator has been completely obviated and, as such, the novelist has become free to abscond. The new dwwaydar is both an inheritor and an originator, inheriting the history, dictatorial past as well as originating the struggle of the individual to gain his pristine and primal self which has been lost somewhere in the mire of history. The suffering of an individual reflects the suffering of the whole nation. The two are closely connected in a way that makes the title of the novel, The Hostage, applicable to both the narrator and the Yemeni people. The writer shows him disgusted with his dirty job, meditating on his sad lot, and indignant at the behavior of the royal family towards him he is to none, not even to his own feelings. For others his actions may be acts of madness as when he attacks the boy of the crown prince but for him these acts of protest bring a fulfillment of personality. Against the background of the atmosphere of the palace, reeking in corruption and immortality, The Hostage finds that his protests are the only of self-fulfillment. When Shariffa Hafsa orders him to be chained, is hurt. Even when one solider come to have his chains taken off, as ordered by her, the Hostage's response is:

"I didn't ask her to."

"Those are her orders."

"Well, I won't go along with them."

Arab World English Journal for Translation \& Literary Studies 
"The soldier will!"

"I'll resist."

"That could cost you dear."

"I don’t care."

I'd come to a firm decision on this, and I was resolved to carry it out'.

In the struggle that follows, the Hostage uses every means he can think of to resist the soldier. Even the servants who gather to break up the fight call his action" unjustified stubbornness." The way the protagonist conducts himself after he discovers the relationship between Hafsa and the poet, shows how he values his dignity. He vows never to return to her house, however long he is kept in chains.

\section{Conclusion}

Dammaj in his novel The Hostage has written a history of humanity around discontinuity or interruption. He uses his fiction as an instrument to present a history, not in terms of a story of the past but in terms of a story of humanity, in terms of culturally privileged and culturally marginalized protagonists and in terms of how the latter try to subvert the former. The conflict in the novel is between individual consciousness and the collective historical agents of the society, making the novel a story of the quest for a new, more equal and more humane society that can better accommodate a new sense of identity. With this narrative strategy and structure, Dammaj has succeeded in managing the dialectics of history and fiction. Combining history and fiction in one person makes the fiction convincing. The man who has suffered the past and the man who is experiencing the present so that he can live with his own self and identity in the future, are the same. Thus the novelist has been able to manage the fiction - time very well and effortlessly., he has been able to give his novel a broad extension in terms of time, covering the past, the present and the future and thus to imbue his novel with timelessness. The novel is not mere history, it is not mere fiction. It has combined both together to create such an art that gives a meaning and significance to the total humanity, to its essence and spirit which are beyond the pale of time. And that is the triumph of true art- of the narrative art that, in itself, is a coherent and stable vision of life- the net result of the totalizing nature of history and fiction. A close reading of the novel The Hostage shows that it is a creation of the re-thinking, on the part of Dammaj, of the concept of history very much similar to that of new historicism. The natural integration of history and fiction makes the Dammaj a natural historian, extracting and presenting a single kernel of meaning. With his narrative art, he is able to manipulate a continuous parallel between contemporaneity and antiquity. He manages to control order and give a shape and significance to the immense panorama of futility and anarchy, which is history; it is an attempt by the present in the form of fiction to give a meaning to the past in the form of history. Thus, the interconnectivity of the two is complete.

\section{About the Author:}

Arab World English Journal for Translation \& Literary Studies 
Dr. Abdurrahman Mokbel Mahyoub Hezam is an associate professor of English literature and comparative studies at the department of English, Faculty of Arts, Taiz University. Currently he is working as Head of the department of Languages and Translation, Faculty of Science and Arts, Taibah University- Al-Ola, Saudi Arabia.

\section{References}

Abrams, M.H. (1993.)A Glossary of Literary Terms (Sixth Edition: Prism Books PVT. Ltd: Bangalore.

Al-Maqalih, A. (1994)," Introduction: Literary Background" The Hostage translation from Arabic by M. Jayyusi and Christopher Tingley published by Interlink Books, New York.

Brannigan, J. (1998) New Historicism and Cultural Materialism. London: Macmillan.

Butterfield, H. (1971). The historical novel; an essay, [Folcroft, Pa.]: Folcroft Library Editions.

Dammaj, Z. M. (1994). The Hostage Tra. M. Jayyusi and Christopher Tingley, Interlink Books, New York.

Dhar, T. N. (1999) History-Fiction Interface in Indian English Novel, Prestige: - New Delhi.

Fleishman, A. (1972). The English Historical Novel: Walter Scott to Virginia Woolf. Baltimore and London: The Johns

Lukacs, G. (1962). The Historical Novel, London: Merlin Press.

Mandelibaum, M. (1967). A Note on History as Narrative, in History and Theory, volume VI, No 1

Peach, L. (2007)."Historical Approaches", in Virginia Woolf Studies ed. Anna Snaith: Plgrave, Macmillan

Zusi, P A. (2004). Echoes of the Epochal: Historicism and the Realism Debate. Comparative Literature, 56, (3) 207-226. 